study of autonomous robots into a recognizable discipline. In addition to technical papers reporting theoretical advances and application examples, the journal accepts papers describing prototype systems as well as tutorials, surveys and essays offering distinct perspectives. There has also been a special issue on autonomous robots for planetary exploration. All the papers seem to be of a high standard expected. The typography and production standards are also good. Good value for money, it deserves to succeed.

Dave Cliff is at the School of Cognitive and Computing Sciences, University of Sussex, Brighton BN1 9QH, UK.

\section{Young pretender}

\section{Laura Garwin}

Journal of Undergraduate Sciences. Editors V. Jain et al.. Variable frequency. For further details contact the subscription department at PO Box 380932, Cambridge, Massachusetts 02238, USA.

GET a few editors of science journals together over a few beers, and it won't be long before the conversation turns to the use of published papers as 'performance indicators', and the distortions that this practice introduces into the publication process. Whereas we editors still cherish the idea that papers are written to convey new research results to fellow scientists who can make some use of them, there are others out there for whom the specific content of published papers seems to matter less than their mere existence.

So I find it rather disturbing that Harvard University's Journal of Undergraduate Sciences - created in 1994 to publish the results of undergraduate research projects - claims in its inaugural issue to be a place for "graduate schools,... science award administrators, and professors... to discover promising young scientists". While most journals reconcile themselves to being used in this way, JUS seems to welcome it with open arms.

Of course, JUS sees itself as more than a marketing device for Harvard undergraduates; its main stated aims are to foster interdisciplinary communication and to encourage undergraduate scientists to write clearly and concisely. The journal is indeed wide-ranging - covering all the sciences, together with history of science and public policy - but then so are other general journals, such as Nature and Science. A JUS editorial complains that papers in these journals are "too focused and too technical" for the undergraduate reader (probably a fair accusation), but then the abstract of a paper in the same issue starts with a sentence ("The Drosophila
International Journal of Polymer Analysis and Characterization

Editor-in-chief H. G. Barth

Gordon and Breach. 4/yr. £340

(institutional); $£ 218$ (library); $£ 75$ (personal).

WITH the continuing development of new polymers that may not be sensitive to welldeveloped characterization methods, new reliable approaches must be devised to evaluate performance. But, as the editors point out, papers detailing such advances are scattered throughout the many existing polymer journals.

A single forum for such articles will, they claim, make it easier for researchers to find this information. Yet despite this emphasis, some of the papers, like those in the older journals, use the results of analysis or characterization to explore theoretical predictions or define physico-chemical behaviour. Not surprisingly, over a third are on chromatographic analysis.

Each issue contains around seven papers (short, long; 'how to', 'what if?'). The printing is clear and the layout good, although figures seem to be reproduced as supplied by the authors. Publication rate is slow (nearly two years between submission and appearance)

But does the journal really fulfil a need? Articles can now be tracked down easily and cheaply using sophisticated software and electronic databases. The journal certainly has a place in industrial and academic establishments where characterization and analysis are important. But many of the papers are of sufficiently good quality to make it into estabished polymer journals, so its success will depend on how well it can compete.

Randal W. Richards Department of Chemistry, University of Durham, Durham DH1 3LE, UK.

melanogaster gene corkscrew (csw) encodes a tyrosine phosphatase important for transducing the signal from a number of receptor tyrosine kinases (RTK's), including torso, sevenless, the fly EGF-receptor homolog torpedo, and the fly FGF-receptor homolog breathless...") guaranteed to scare away the most resolute physics undergraduate - or $\mathrm{PhD}$, for that matter.

Sadly, the guide to authors positively encourages bad habits, such as the use of the passive voice (which can actively hinder comprehension, by obscuring the distinction between new work and old) and the confusing use of the plural pronoun 'we' for a single author. Even more worrying is the suggestion that "if your original hypothesis was not validated by your results, then it is appropriate to analyze your methods and procedures for systematic errors or incomplete control of all variables" - surely it is appropriate to do this whether or not one's hypothesis has been validated!

The journal is proud of its peer-review process, undertaken by Harvard graduate students and professors. But how rigorous can such a process be, when other journals have to comb several continents for truly
International Journal of Forensic Document Examiners

Editor Joel S. Harris

Shunderson Communications, PO Box

42057, Ottawa, Ontario, Canada K1K 4 L8 $\$ 40$ (institutions): USA and Canada, $\$ 30$. elsewhere $\$ 35$ (personal)

IN 1974 the American Academy of Forensic Sciences established a certification programme for several fields, including organization of an American Board of Forensic Document Examiners. No academic institution yet awards a degree in forensic document examination, but there are now around 200 certified diplomates in the US and Canada.

The need for examination of documents arises mainly in criminal cases. International Journal of Forensic Document Examiners claims to be the first journal devoted entirely to this subject. Its presents peer-reviewed research articles, technical reports and case studies on subjects including handwriting, mechanical printing devices, security documents, plastic cards, altered documents, charred and/or water-soaked documents and chemical analysis of media used in document preparation.

Nearly all of the contents consist of reprints from other sources. Most articles were presented at conferences. The journal also publishes abstracts of papers and accounts of news based on reports in newspapers, and offers to print free announcements of relevant meetings. Descriptions of new equipment appear but the distinction between editorial reports and paid advertisements is not made clear. Most reports are anecdotal and there is little of general scientific interest. But the journal serves a small group of specialized technologists and presents an abundance of material.

Lee Loevinger Hogan and Hartson, 555 Thirteenth Street, NW, Washington DC 20004 1109, USA.

expert referees? The answer is that, for all its worthy aims, JUS is really just a makebelieve journal. The papers fall into two categories: those that are 'just' undergraduate research papers (some have reference lists that cite only textbooks, with perhaps a sprinkling of very old research papers) and those that may be valuable contributions to the scientific literature. The former don't need to be published at all - which isn't to say that they shouldn't be written, and examined critically by professors - but the latter ought to be published in a 'real' journal, where they will be seen by others in the field. JUS seems to care about everything except what a journal is really for - the communication of research results to the relevant audience.

Undergraduate scientists do need to learn how to write clearly and concisely, but also how to judge whether their results make a valuable new contribution to a field of knowledge. Allowing them to be big fish in a small pond - even a highly regarded pond - is likely to stunt their growth.

Laura Garwin is physical sciences editor of Nature. 